todas as areas, mas que talvez o seja especialmente para um campo onde a responsabilidade social ê mais evidente, como o da saúde. O livro de Edith é, em si, um exemplo de como se dá esse compromisso, como salienta o prefácio de Mauricio Tragtemberg.

A pesquisa vinculada a uma estrutura organizacional que reflete interesses econômicos não pode revelar $o$ sofrimento humano que ela mesma provoca. É por esta razão que Edith opta pelo compromisso com os interesses dos trabalhadores, pois o seu objeto é o sofrimento destes. Assim, enquanto o compromisso com a logica empresarial pode concentrar-se em temas como o aumento de produtividade, o compromisso com os interesses dos trabalhadores centra-se em temas como a superexploração.

A ambição da autora é grande. Para ela, saúde mental no trabalho näo é um tema circunscrito ao campo da psiquiatria, mas o é, tambëm, de recursos humanos $e_{\text {, }}$ mais amplamente, de administração.

É funçâo da universidade formar, em prazo curto, profissionais capazes de manejar essas questốes e promover, de forma útil e produtiva para os trabalhadores, 0 ensino da psicologia do trabalho. $O$ ensino desta disciplina é, hoje, algo muito desafiador, já que implica questôes éticas, políticas e de divisäo internacional do trabaIho. A isso acrescentar-se-iam questôes culturais.

A parte inicial da obra de Edith, professora da EAESP/ F GV, delineia o campo de estudo da saúde mental do trabalho. Ela destaca que o trabalho tanto pode ser agente de promoção da saúde mental quanto promotor de distürbios de expressão coletiva, em termos psicossociais, ou, ainda, de expressäo individual.

Outro foco de análise da autora sâo as contradiçöes entre as necessidades económicas no mundo do trabalho. A abordagem que adota acaba por identificar a forma pela qual os diferentes campos tendencias das ciências sociais se inserem no campo multidisciplinar da saúde mental no trabalho, muito mais amplo do que o dos pesquisadores sociais, por incluir tamberm aqueles de ciencias exatas e biológicas.

A preocupação comum dos pesquisadores da saúde mental do trabalho é selecionar os aspectos que, potencialmente, teräo impacto sobre os trabalhadores. Evidentemente, essa preocupação é acompanhada de outra, a de encontrar articulaçăo interdisciplinar entre os pesquisadores ou entre as pesquisas. Edith Seligmann Silva deixa isso claro quando delineia o histórico da psicologia do trabalho, mostrando como sua evoluçâo se entrelaça com o surgimento da ergonometria e da própria saúde mental no trabalho.

Nessa parte da obra, salienta-se uma área identificada pela autora como "nova psicopatologia do trabalho", que ocupa posição central no campo da saúde mental no trabalho. A ideia de considerar essa nova ărea deve-se às suas bases conceituais e procedimentos metodo- lógicos, inteiramente diversos do referencial da psiquíatria clássica.

Assim, para Edith, é com Dejours (DEJOURS, C. ADBOUCHELI, E. Itineraire theorique en psychopathologie du travail. Prevenit, Marselha, v. 20, p. $127-49$, 1990.) que se assentam as bases da saúde mental no trabalho, na vertente "psicopatologia do trabalho", que "se dedica à analise dinânica dos processos psiquicos mobilizados pelo confronto do sujeito com a realidade do habalho".

O livro de Edith Seligmann Silva, enfim, não é um trabalho para especialista. É para ser lido por todos os que respeitam e defendem a dignidade do trabalhador; como muito bem salienta Mauricio Tragtemberg.

\section{WHAT IS JAPAN: CONTRADICTIONS AND TRANSFORMATIONS}

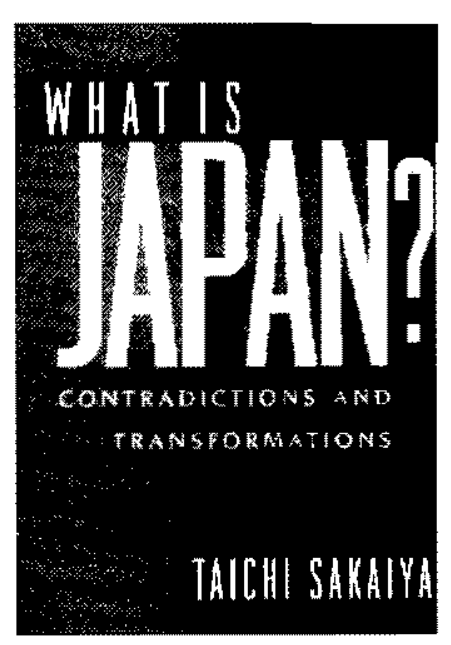

de TAICHI SAKAIYA, traduçăo de Steven Karpa. New York: Kodansha International, 1993, 312 p.

por Gilmar Masiero, Pesquisador e Professor da Universidade Estadual de Maringat, PR.

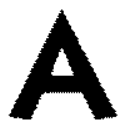
reaçăo alemã à modernidade, com sua celebraЂ̆̃o da comunidade, do solo, da cultura aristocrática e da singularidade teutônica, com seu hostil repudio à "decadente" burguesia e ao cosmopolitismo democrático ocidental, propiciou, sob várias formas, o surgimento de políticos e intelectuais conservadores fortemente engajados na defesa da autoridade da tradiçäo. Antes da Segunda Guerra Mundial, era comum a questāo "O que é a Alemanha?" e agora Taichi Sakaiya repete a questão "O que é o lapĩo?" $\mathrm{e}$, seguindo a tradiçäo, fornece suas próprias respostas.

Taichi Sakaiya é apresentado aos leitores da lingua inglesa como um japonês nascido em Osaka em 1935. Após ter recebido o diploma de economista na Universidade de Tokyo, desenvolveu carreira burocrática junto ao Mínistério do Comércio Internacional e Indústria 
(MIT), onde foi responsável pelo planejamento e realizaçăo da Exposição de Osaka em 1970 e da Exposição de Okinawa em 1975. Após ter deixado o ministério, transtormou-se num autor best seller no Japão, publicando mais de 30 livros, extensamente lidos e discutidos. Sua presença nos meios de telecomunicações de massa já é rotineira no Japão. The knowledge-value revolution foi seu primeiro livro a ser traduzido para o inglés.

É muito difícil destacar uma ou outra idéía de um livro que tem como temática central o Japão. Sakaiya procura apresentá-lo na totalidade de seu desenvolvimento historico, centrado nas suas particularidades éticas e estéticas ou mesmo de suas peculiares condiçôes climáticas, geográficas e populacionais. Contrastando, ora com o desenvolvimento chinès, ora com o romano, ou mesmo com o desenvolvimento anglo-saxônico contemporâneo, o autor reapresenta o Japăo desde os primórdios da cultura Jamon e Yayoi ( 400 a.C.) até a era moderna do pós-Segunda Guerra Mundial.

Essa apresentação, que na sua totalidade é de excelente nivel descritivo e informacional, deixa a desejar; no entanto, quanto ao subtítulo do livro: Contraditions and transformations. Se as transformaçoes săo cronologicamente bem apresentadas as contradiçōes muitas vezes apontadas carecem de maior análise e explicaçâo. Isto, porém, não impede à aguçada visão do autor de perceber o lapão como um país onde os produtores são louvados e os consumidores considerados ordinários e de qualidade inferior.

Nas palavras de Sakaiya, a "sociedade otinizada industrialmente fez o Japaro rico" e produziu um país com "preços altos, alugués caros, trens e aeroportos superlotados de pessoas. Para conseguir uma cama num hospital, você precisa de conecçōes. Os procedimentos burocráticos governamentais são complicados; rotinas oficiais ou procedimentos sāo marcados por excessizx complexidade que resultam em atrasos e demoras desnecessáríns. Porếm, mais frustrante que tudo isso, é a pobreza de escollo".

Esse Japão, retratado como o "paraíso dos produtores e o inferno dos consumidores", fácil leitura e compreensão. Para os não-iniciados na discussão sobre o Japáo e sobre o grande dinamismo econômico e cultural do Oriente, sugere-se iniciar a leitura pelos principais eventos da história japonesa, apresentados no final do livro. Sugere-se também uma cuidadosa leitura do glossário que, além de explicativo, serve para introduzir o leitor nos conteudos apresentados na obra.

A acurada percepção do desenvolvimento histórico japonès é apresentada aos leitores ocidentais após tex sido apresentada aos leitores japoneses, em 1991, sob o mesmo título: Nihon to wa nani $k a$. Nesta versäo inglesa, um prefácio e um epílogo foram acrescentados para que, além dos esclarecimentos rotineiros, fosse enfatizado, de alguma forma, o centralismo cultural que permeia todo o livro, organizado em seis partes subdivididas em 20 capítulos.

A primeira parte, Japăo nos anos 90 , é apresentada através de $Q$ uase um paraíso; $O$ rico país que não se sente rico e A realidade do paraíso Japâo: a monocultura industrial. Nessa parte, o autor caracteriza a supremacia da burocracia japonesa sobre as demais esferas da vida social e apresenta o estilo de administraçäo e o estilo de cooperação entre governo e grandes empresas como variáveis explicativas do sucesso econômico japonês. Sucesso este que náo dispensou "o sistenta de controle adntinistratizo e cooperação industrial implantado em $1941-e$ prosperando por mais de 50 anos".

Paz, cooperaçấo e ambiente é o subtítulo da segunda parte, onde o autor enfatiza o espírito de trabalho em grupo descrevendo o início da agricultura no Japäo. Ao capítulo A cultura japonesa começou nos campos de arroz, segue-se Amortecido por uma proteção oceânica grande o suficiente e Uma pacífica sociedade que confia em seus superiores. A terceira parte, Crescidos para serem bons aprendizes, procura enfatizar os aspectos religiosos da sociedade japonesa ao longo de sua história nos capítulos: Shinto e Budismo: duas religióes de uma vezz, Inexistência de um bom absoluto, Os prós e contras da adoção seletiva, Disputa entre civilização e tradiçāo japonesa.

A quarta parte, Sombras governamentais e a cultura da simplicidade, procura retratar a formaçăo e o domí nio do espírito militar japonês na época em que Kamakura tornou-se o centro do poder real e Kyoto permanecia como centro do poder imperial. Essa parte é apresentada através dos capitulos: Grupos comunitários japoneses, Cidades sem muros, Sistemas que separam a aparência da realidade e A cultura da simplicidade que evita ser contra o natural.

Recursos e populaçäo afetam a civilização é a temática apresentada na quinta parte do livro de Sakaiya através dos capítulos: Sociedades de escassez e abundância, Fatores formadores da civilização japonesa e Cultura japonesa de diligência e softzare. A sexta e ultima parte, Os limites da prosperidade na sociedade industrial definitiva, é apresentada através da Estrada para a sociedade industrial definitiva, $O$ s primeiros dias do controle administrativo $\mathrm{O}$ limites da sociedade industrial definitiva: as próximas transformações japonesas.

A leitura do livro de Sakaiya é recomendada aos estudiosos do Japão, não só pela legitimidade de grande escritor adquirida pelo autor através dos seus muitos livros, mas também pela sua ativa carreira de burocrata no ministério freqüentemente apontado como um dos grandes responsáveis pelo sucesso econômico japonês do pós-guerra. Sendo uma visão geral de todo o desenvolvimento japonês, a obra é também recomendada a todos os leitores ocidentais năo-familiarizados com o desenvolvimento oriental. $\square$ 